\title{
Mulheres marcadas: prostituição, ordem e exclusão
}

\author{
Marked women: prostitution, order and exclusion
}

\author{
Octávio SACRAMENTO \\ Universidade de Trás-os-Montes e Alto Douro \\ riosacra@portugalmail.pt \\ Manuela RIBEIRO \\ Universidade de Trás-os-Montes e Alto Douro \\ ribmac@gmail.com
}

Recibido: 10/04/2013

Revisado: 20/08/2013

Aceptado: 01/10/2013

Disponible on line: $27 / 06 / 2014$

\begin{abstract}
Resumen
En el artículo debatimos los procesos estigmatizantes sobre las mujeres que ejercen la prostitución de club en el segmento de la frontera Ibérica situado entre los ejes transfronterizos Montalegre-Xinzo de Limia y Bragança-Alcañices/Zamora. Desde la perspectiva del interaccionismo simbólico sobre la estigmatización como proyección relacional inscrita en disensiones entre actores o grupos ubicados en diferentes cuadrantes morales, consideramos como objetivos principales: (i) mapear dinámicas sociales de producción de estereotipos peyorativos sobre la prostitución, (ii) interpretar sentidos presentes en las acciones estigmatizantes, (iii) comprender la relevancia de la etnicidad y de la corporeidad de las mujeres visadas en la activación/refuerzo de estas acciones, (iv) identificar algunos de los efectos generados por la represión interpersonal e institucional del sexo mercantil, (v) mostrar la omnipresencia del estigma puta como forma de violencia simbólica sobre las mujeres en general, disciplinando cuerpos y comportamientos. Buscamos, de este modo, la comprensión de la mecánica social, contenidos, razones, consecuencias y amplitud de los estigmas dirigidos a las trabajadoras sexuales, teniendo presente que ahí residen muchos de sus mayores problemas y, por lo tanto, muchos de los desafíos prioritarios que se colocan a la intervención social en el ámbito de la prostitución.
\end{abstract}

Palabras clave: prostitución, estigmas, orden moral, represión, controlo de la feminidad.

\begin{abstract}
In the article, we debate the stigmatizing processes on women engaged in club prostitution in the section of the Iberian frontier located between the cross-border axes of Montalegre-Xinzo de Limia and BragançaAlcañices/Zamora. From the perspective of symbolic interactionism about stigmatization as a relational projection embedded in dissensions between actors or groups situated in different moral spaces, we consider as main objectives: (i) map the social dynamics of the production of derogatory stereotypes about prostitution, (ii) interpret meanings present in the stigmatizing practices, (iii) understand the relevance of women's ethnicity and corporeal nature in the activation/reinforcement of these practices, (iv) identify some effects produced by the interpersonal and institutional repression of commercial sex, (v) show the ubiquity of the whore stigma as a form of symbolic violence against women in general, disciplining bodies and behaviors. We seek, in this way, an understanding of social mechanics, contents, reasons, consequences and breadth of the stigmas aimed at sex workers, keeping in mind that therein reside many of their major problems and, therefore, many of the priority challenges to social intervention in the field of prostitution.

Keywords: prostitution, stigmas, moral order, repression, femininity control.
\end{abstract}

\section{Resumen amplio}

El artículo tiene como finalidad comprender los procesos estigmatizantes que experimentan las mujeres que ejercen la prostitución en clubes, a partir de una investigación realizada en el territorio transfronterizo de Montalegre (Xinzo de Limia y Bragança) y Zamora (Alcañices). Las mujeres que participaron en el trabajo de campo y cuyos discursos acompañan los resultados de la investigación fueron, en su gran mayoría, de origen sudamericano. 
El enfoque de análisis, que se apoya en los presupuestos del interaccionismo-simbólico, pretende fundamentalmente poner de relieve los procesos sociales estigmatizantes de uno de los colectivos con mayor censura moral y, en consecuencia, señalar los efectos que de aquí se derivan para la vida cotidiana de estas mujeres. El estigma es un factor poderoso de marginación social y, por ello, es importante comprender la violencia simbólica que se ejerce a través de algunas tramas discursivas o en palabras como puede ser, en este caso, la de «puta».

Es necesario saber que estos discursos no sólo aluden o pueden afectar a las trabajadoras sexuales sino, también, pueden funcionar como instrumentos de control de la sexualidad femenina en general, al establecer un ordenamiento moral entre buenas y malas mujeres, así como disciplinando cuerpos y comportamientos. Esta idea se sostiene al comprobar que los marcadores más relevantes encontrados en el proceso de estigmatización no apuntan directamente a la actividad ejercida (la prostitución) sino a las características físicas, la pertenencia nacional, la etnicidad, el comportamiento extrovertido/exuberante, el vestuario, etcétera. Esta mirada más amplia atraviesa el análisis de la investigación y supone una de sus conclusiones centrales.

Los autores entienden la estigmatización como un proceso eminentemente relacional donde se produce un deterioro identitario entre actores inscritos en diferentes perspectivas morales, $\mathrm{y}$, por tanto, los objetivos principales que se han desarrollado a lo largo del texto son los siguientes: (i) mapear dinámicas sociales de producción de estereotipos peyorativos sobre la prostitución, (ii) interpretar sentidos presentes en las acciones estigmatizantes, (iii) comprender la relevancia de la etnicidad y de la corporeidad de las mujeres en la activación/refuerzo de estas acciones, (iv) identificar algunos de los efectos generados por la represión interpersonal e institucional del sexo mercantil, (v) mostrar la omnipresencia del estigma puta como forma de violencia simbólica sobre las mujeres en general.

Se trata, en definitiva, de comprender la mecánica social, los contenidos, las razones, las consecuencias y la amplitud de los estigmas dirigidos a las trabajadoras sexuales, teniendo presente que ahí residen muchos de sus mayores problemas y, por lo tanto, muchos de los desafíos prioritarios que se colocan a la intervención social en el ámbito de la prostitución.

Referencia normalizada: Sacramento, O., y Ribeiro, M. (2014): «Mulheres marcadas: prostitução, ordem e exclusão». Cuadernos de Trabajo Social, 27(1): 197-209.

Resumo: Introdução. 1. Marcas da (des)ordem. 2. Exotismos e estereótipos sexualizados. 3. Repressão e exclusão. 4. Concluindo: o estigma como meio de controlo da feminilidade. 5. Referênces.

\section{Introdução}

As reflexões que aqui desenvolvemos decorrem de um estudo sobre prostituição feminina em regiões de fronteira ${ }^{1}$ e têm como grande referência teórica a obra que dele resultou - $\mathrm{Vi}$ das na Raia (Ribeiro, Silva, Schouten, Ribeiro e Sacramento, 2007) - , retomando e actualizando perspectivas de análise aí delineadas. No seu todo, o projecto em questão considerava, para efeitos de pesquisa empírica, uma fai- xa territorial transfronteiriça (cerca de $50 \mathrm{~km}$ para cada um dos lados da linha de fronteira Ibérica) delimitada pelos eixos Braga-Vigo e Guarda/Vilar Formoso-Fuentes de Oñoro. O terreno afecto à equipa da UTAD, que integrámos, circunscreveu-se ao segmento situado entre Montalegre-Xinzo de Limia e BragançaAlcañices/Zamora, sendo, portanto, o contexto a que mais diretamente se referem os conteúdos deste texto ${ }^{2}$. Com um perfil de pendor ru-

${ }^{1}$ Projecto SAPIENS/99 POCT1/36472/SOC, financiado pela Fundação para a Ciência e Tecnologia (FCT-Portugal) e concretizado por uma equipa de três universidades portuguesas: a de Trás-os-Montes e Alto Douro (UTAD), a do Minho (UM) e a da Beira Interior (UBI).

${ }^{2} \mathrm{O}$ trabalho de campo que desenvolvemos neste contexto privilegiou uma abordagem de natureza qualitativa, destacando-se a observação-participante e as entrevistas semi-dirigidas como procedimentos metodológicos fundamentais. A investigação circunscreveu-se aos espaços específicos da prostituição e, ainda que de forma menos intensiva, aos contextos sociais mais amplos em que eles estão inseridos. Deste modo, foi-nos possível explorar as intercepções existentes entre uns e outros, ou seja, os respectivos processos de interacção e os discursos cruzados que lhes andam associados. 
ral, este é um território periférico onde a prostituição, como actividade organizada, para além de fenómeno relativamente recente (finais dos anos 1980$)^{3}$, vem sendo exercida em ambientes abrigados, nomeadamente em estabelecimentos conhecidos como clubes. As mulheres que aí encontrámos à data da realização do trabalho de campo eram, na sua grande maioria, de origem sul-americana ${ }^{4}$. A sua vinda para exercer esta actividade na Europa decorreu, segundo as respostas da generalidade das inquiridas, de uma escolha pessoal e para a sua concretização contaram, quase todas, com a ajuda de redes sociais não criminosas, baseadas em laços de parentesco, amizade ou vizinhança. Visitas mais recentes ao terreno permitiram-nos constatar do lado espanhol o aumento do contingente de mulheres de alguns países do leste da Europa (v.g. Roménia), para o qual terá contribuído, certamente, a sua integração na União Europeia (UE).

$\mathrm{O}$ enfoque de análise que aqui desenvolvemos centra-se nos processos sociais estigmatizantes de que são alvo as mulheres que exercem a prostituição, mais especificamente as que o fazem em clubes no contexto acima referenciado. Pertencendo a um dos colectivos alvo de maior censura moral em quase todo o mundo (Oselin, 2009), a estigmatização é identificada pelas próprias e por terceiras pessoas como um poderoso constrangimento e factor de marginalização nos seus quotidianos de vida (Juliano, 2005; Ribeiro e Sacramento, 2005; Seshu, 2008; Liberto, 2009; Tomura, 2009; Oselin, 2010; Sallmann, 2010; Oliveira, 2011a). Esta opressão por via da «violência simbólica» (Bourdieu, 1999) tem como grande referencial discursivo o rótulo puta; uma construção social que «poderá ser considerada paradigma das atribuições de vergonha» (Scambler, 2007, p. 1079) e que não afecta apenas as trabalhadoras sexuais. Ela funciona, também, como instrumento difuso de controlo da sexualidade feminina em geral (Pheterson, 1993, 1996;
Oliveira, 2009), estabelecendo um ordenamento moral de boas e más mulheres, e disciplinando corpos e comportamentos.

Partindo do pressuposto interaccionista-simbólico (Becker, 1966; Lemert 1972; Goffman, 1982) de que a estigmatização é um processo eminentemente relacional de deterioração identitária entre actores inscritos em diferentes quadrantes morais, procuraremos: $(i)$ mapear a sua organização, (ii) interpretar os principais significados presentes nas acções estigmatizantes, (iii) compreender a relevância da etnicidade e da corporeidade das mulheres visadas na activação/reforço destas acções, (iv) identificar alguns dos efeitos gerados pela repressão social do sexo mercantil, $(v)$ mostrar a omnipresença do estigma puta enquanto construção que, implicitamente, prescreve modelos normativos de intimidade para a generalidade das mulheres. Procuramos, deste modo, o entendimento da mecânica social, conteúdos, razões, consequências e amplitude dos estigmas dirigidos às trabalhadoras sexuais, tendo presente que aí residem muitos dos seus maiores problemas e, por isso, muitos dos desafios prioritários que se colocam à intervenção social no campo da prostituição.

\section{Marcas da (des)ordem}

Os estigmas que visam o exercício do trabalho sexual são construções embebidas numa determinada ecologia histórica (Hallgrímsdóttir, Phillips, Benoit e Walby, 2008), ainda que, num processo de essencialização do social, tendam a ser percebidos como produtos intemporais e naturais (Guimarães e Merchán-Hamann, 2005). A actividade nem sempre foi objecto de estigmatização, nem as mulheres que a ela se dedicam vistas como desviantes. Em todo o mundo antigo há exemplos que nos mostram que elas detinham um estatuto de grande relevo social. Nas cidades da Mesopotâmia e do Egipto, a grande deusa Innana, mais tarde Ishtar, era identificada como uma prostituta e muitas das mulheres que se prostituíam eram conside-

\footnotetext{
3 À excepção dos tradicionais barrios chinos em Espanha, como o de Zamora.

${ }^{4}$ Sobretudo de nacionalidade brasileira. A presença de mulheres oriundas do Brasil era particularmente notória do lado português, em especial nas regiões de Chaves e de Bragança. Do outro lado da fronteira, já em territórios da Galiza e de Castilla y León, a presença de brasileiras também era considerável, embora superada pela de mulheres hispânicas, nomeadamente colombianas e dominicanas. Sobre as mulheres que exercem a "prostituição abrigada», bem como sobre o perfil de localização, características e funcionamento dos clubes, ver Ribeiro e Sacramento (2002) e Ribeiro et al. (2007).
} 
radas sagradas, detendo uma grande capacidade de influência nas esferas religiosa, política e económica, (Roberts, 1996; Ringdal, 2004; Leick, 2008) $)^{5}$. De igual modo, na Grécia antiga eram mulheres de elevada posição social e portadoras de níveis educacionais muito acima da média. Só com o advento da moral sexual imposta pela tradição judaico-cristã é que a prostituição passa a ser construída como sinónimo de devassidão (Ringdal, 2004) e alvo de forte controlo e repressão.

Indissociável do tempo histórico, o estigma resulta de «um processo relacional, circunscrito no tempo e no espaço, pelo qual um grupo de actores projectou noutro grupo de personagens certos atributos que lhe conferiram marginalidade e justificaram o seu exílio do tecido social» (Bastos, 1997, p. 14). Trata-se, como destaca Goffman (1982), de um atributo que não se enquadra nas expectativas normativas que regulam as construções identitárias e a definição dos papéis sociais. É justamente esta divergência que é tomada como móbil para macular o status e depreciar a identidade, mesmo que a letra da lei, tal como acontece com o exercício da prostituição em Portugal e em Espanha, não identifique a situação como uma ilegalidade ${ }^{6}$. A prostituta é estigmatizada não por estar a cometer qualquer infracção legal, mas pela sua divergência face aos valores dominantes que regulam a sexualidade feminina e estabelecem uma ideia moral de ordem.

O estigma não é uma característica intrínseca da pessoa. Como destacam os «labelling theorists» da corrente do interaccionismo simbólico, ele é «uma consequência da aplicação por outras pessoas de regras e sanções a um 'transgressor'» (Becker, 1977, p. 60); uma produção simbólica que determinados indivíduos ou grupos sociais, agindo sob determinadas condições sócio-históricas, fazem incidir sobre outros nas interacções que com eles estabelecem (Ribeiro e Sacramento 2012). A génese das representações estigmatizantes remete, quase sempre, para a ansiedade social dos seus produtores em salvaguardar a integridade das fronteiras da sua própria identidade. $\mathrm{O}$ espectro da ameaça é imputado por via do estigma a todos aqueles que, ao manifestarem especificidades divergentes do sistema hegemónico de normas e valores são, simbolicamente, assumidos como focos de impureza e de poluição social (Ribeiro et al., 2007), em relação aos quais se torna imperioso criar «defesas morais» (Nahra, 2000) e prevenir potenciais perigos de contágio e deterioração da identidade. Como nota Douglas (1976, p. 14), «as crenças em poluição podem ser usadas num diálogo reivindicativo e contra-reivindicativo de status [...] e como analogias para expressar uma visão geral da ordem social»».

Deste modo, são geradas diferenças ou exacerbadas clivagens já existentes. É reforçada a ideologia do desvio e fomentada a exclusão, impondo-se o poder da ordem sobre os dissidentes identitários. Este poder é de tal modo intenso que os estigmatizados tendem a assumir e a percepcionar-se segundo os valores sociais que os desacreditam (Tomura, 2009; Oliveira, 2011b) - «felt stigma» (Goffman, 1982; Scambler, 2004; Abel e Fitzgerald, 2010): $O$ que eu faço não é um bom exemplo, principalmente para a minha irmã, pois quando for chamar a atenção dela não tenho moral! (brasileira, 25 anos). A interiorização e experiência subjectiva do estigma faz-se, geralmente, por referência a valores religiosos: Quando comecei, senti-me muito mal, porque era contra os princípios evangélicos com que fui educada! (brasileira, 34 anos); Na Bíblia há vários provérbios que falam da mulher prostituta. Leio isso e sinto um peso na consciência, mas é.. é mais uma conversa com Deus que um reza. Ai, na conversa, eu sempre peço perdão (brasileira, 26 anos). Enquanto actividade considerada imoral, sabem que aquilo que fazem não bene-

5 Importa, todavia, ressalvar a existência de perspectivas que colocam em causa a «prostituição sagrada» como realidade histórica, encarando-a, acima de tudo, como uma construção mitológico-literária (Budin, 2006).

${ }^{6} \mathrm{O}$ enquadramento jurídico da prostituição em Espanha e Portugal é muito semelhante e, em ambos os casos, ambíguo. A actividade não é considerada crime, mas também não é reconhecida como legal. O que é considerado crime, nomeadamente em Portugal, é a prática de lenocínio: promoção da prostituição com objectivos económicos por parte de terceiras pessoas (Gonçalves, 2007). Embora com leis similares, em Espanha parece existir uma maior tolerância das forças policiais em relação ao funcionamento dos clubes (Hart, 1998). 
ficiará de tolerância social, mesmo no respectivo círculo familiar:

- Se a família souber, pode desculpar, mas há momentos em que isso pode vir à conversa ou alguém me atirar à cara que eu já fui prostituta (brasileira, 23 anos);

- Se essas pessoas [família] soubessem, eu ia perder o respeito delas. E o respeito dessas pessoas é muito importante! Aos olhos das pessoas, eu estou fazendo uma coisa má! (brasileira, 31 anos);

— Eu tenho vergonha. Eles [familiares] são preconceituosos demais. Eles iriam me discriminar, me desprezar! (brasileira, 28 anos).

Contudo, algumas destas mulheres nem sempre aceitam, nem reconhecem qualquer legitimidade às apreciações negativas que lhes são dirigidas (Sallmann, 2010). Esta resistência, como é destacado por Abel e Fitzgerald (2010, p. 242), «[...] meant no internalising the stereotypical labels, but speaking out against those who tried to stigmatise $[\ldots]$... Para o efeito desenvolvem discursos de justificação do seu estilo de vida e de questionamento da justeza dos pontos de vista daqueles que se apresentam como estando do lado da normalidade: Isto [prostituição] é um sacrifício pelos nossos filhos. E aquelas mulheres (e há tantas, meu Deus!) que transam [têm relações sexuais] com este, com aquele, com o outro??! Essas não é por necessidade! Essas são o quê?!» (brasileira, 35 anos). Os encargos associados à maternidade são invocados por muitas delas na tentativa de conferir alguma legitimidade à sua actividade. Basicamente, procuram mostrar que fazem o que fazem acima de tudo porque são (boas) mães (Ribeiro 2004).

\section{Exotismos e estereótipos sexualizados}

A observação etnográfica dos contextos em que estão implantados os clubes e da forma como as comunidades locais lidam com a proximidade face ao fenómeno da prostituição permitiu-nos uma compreensão densa dos estigmas projectados sobre as mulheres que prestam serviços sexuais. As comuns representações sociais destas mulheres oscilam, de forma paradoxal, entre o paradigma da vítima ${ }^{7}$ e o da vilã, embora as evidências empíricas nos mostrem que elas não são, necessariamente, nem vítimas, nem vilãs (Pons e Serra, 1998; Ribeiro et al., 2007). No domínio do senso comum, constatámos, todavia, que o paradigma da vilã tende a assumir uma certa hegemonia representacional. Assim, por contraposição à figura social da mulher-esposa-mãe, as trabalhadoras sexuais são representadas como mulheres da noite, mulheres de vida fácil, sem vergonha para vender o próprio corpo, e moralmente, desregradas (Ribeiro et al., 2007).

Em inúmeros espaços da esfera pública registámos, pessoalmente, comportamentos ( $v . g$. olhares inquisitórios, gestos desdenhosos, dedos apontados, cuspir ostensivamente para o chão) e comentários (v.g. olha as putas, que escandalosas), em especial de cidadãos do sexo feminino, denunciadores dos preconceitos sobre as mulheres que se dedicam à prática da prostituição. As trabalhadoras sexuais que entrevistámos têm, de resto, uma consciência muito nítida dos sinais e expressões da recriminação social que lhes é dirigida: Quando saio à rua parece que as pessoas me olham de maneira diferente! Prefiro ficar em casa (brasileira, 29 anos); Sinto que me apontam o dedo, sinto que todo o mundo está a olhar para mim, me censurando! (brasileira, 26 anos). A estigmatização e a contestação social, sobretudo do lado português, incidiu predominantemente sobre as prostitutas provenientes do Brasil. E apesar de haver também mulheres de outras nacionalidades, o certo é que, socialmente, foi produzida uma estreita equivalência simbólica entre prostituta e brasileira. A nacionalidade constitui, assim, um dos principais elementos a suscitar os discursos e as práticas estigmatizantes, como as próprias visadas reconhecem:

- Porque quando as pessoas me olham, antes mesmo de elas me olharem, só de me olhar no espelho eu já..., sabe, e então me incomoda o olhar das pessoas. Porque pelo facto de eu ser brasileira já é uma questão para eles ficarem me

${ }^{7}$ No qual surgem como mulheres vulneráveis face às imposições de redes internacionais de tráfico, clientes e proprietários de clubes. Mesmo quando são tidas como vítimas, os estigmas continuam presentes (Pheterson, in Jacobsen e Skilbrei, 2010, pp. 197 e 205). 
olhando e sabendo que brasileira vem para cá exactamente para se prostituir (brasileira, 34 anos).

No caso concreto de Bragança - uma pequena cidade raiana do nordeste de Portugal com cerca de 20.000 habitantes - tornou-se até bastante frequente as pessoas referirem-se às brasileiras de Bragança enquanto forma de designação das trabalhadoras sexuais da localidade. Como se todas as mulheres brasileiras que aí vivem fossem prostitutas. A existência de uma clara preponderância de mulheres provenientes do Brasil na prostituição propiciou, desde $\operatorname{logo}$, a transmissão do estigma para a generalidade das imigrantes femininas da mesma nacionalidade (Duarte, 2012) ${ }^{8}$. Por outro lado, não podemos esquecer que este processo de disseminação de representações desqualificantes de matriz sexual tem sido potenciado, em certa medida, pelas imagens (hiper)sexualizadas vinculadas à brasilidade (Piscitelli 2007, 2008; Ribeiro e Sacramento, 2009), bem presentes nos discursos que a sociedade portuguesa e muitas outras produzem sobre o Brasil (Pontes, 2004; Scott, 2010). É também em função destas imagens que os estereótipos mais comuns apresentam a brasileira em Portugal e, mais especificamente, em Bragança como prostituta, obliterando a existência de muitas outras mulheres (a maioria) que trabalham em demais actividades. Essas, embora não se prostituindo, acabam por apanhar a fama (estigma): Essas apanham por tabela! Não escapam à fama. Mesmo que as pessoas tenham a certeza que trabalham noutra coisa qualquer, se calhar ficam sempre a desconfiar que elas já andaram na noite! (cliente de clubes, 32 anos) $)^{9}$.

Apanham a fama porque, tal como as suas compatriotas a trabalhar na prostituição, evidenciam alguns atributos que o imaginário social local utiliza como recursos na construção da imagem actualmente predominante da mulher prostituta. Referimo-nos a elementos físicos ou de natureza sociocultural aos quais os indivíduos, tendo em conta as normas, valores e sistemas ideológicos que regulam as estruturas sociais em que estão inseridos, atribuem uma determinada conotação simbólica, tomando-os como referências centrais no processo de etiquetagem e (des)qualificação social. O conjunto destes elementos constitui, deste modo e neste caso, o grande vector de incidência do estigma puta. Em relação às brasileiras -a maioria com traços fenotípicos mestiços, enquadráveis na concepção sexualizada da mulher mulata - , os marcadores mais relevantes e instrumentalizados no processo de estigmatização remetem, de um modo geral, para a nacionalidade, a etnicidade e a $\langle\text { raça }\rangle^{10}$ : características físicas (destacando-se a cor da pele), o sotaque ou alguns adereços a denunciar a pertença nacional, o comportamento extrovertido/exuberante e o vestuário; estes dois últimos tidos como algo 《atrevidos» e 《excêntricos» para os padrões locais: Em Bragança as pessoas não estavam habituadas a ver miúdas só com dois palmos de saia (jornalista local, 63 anos). Assim se compreende como «a corporeidade do 'outro' serve como principal marcador da sua alteridade $»^{11}$ (Wolputte, 2004, p. 252).

${ }^{8} \mathrm{Na}$ Noruega aconteceu um processo semelhante com as mulheres russas, de acordo com a descrição de Sverdljuk (2009, p. 137): «As the local media and public consciousness had a tendency to associate the emerging trans-national prostitution activities solely with 'Russian women', the derogative and vulgar 'stigma of prostitution' rapidly came into being. Russian migrant women in Northern Norway, including the socalled marriage migrants and students, have experienced whore-calling, sidelong glances and insults in everyday life».

9 Da mesma forma que não escapam à fama no seu país de origem, onde, como muitas das que entrevistámos reconheceram, ao saber-se que vêm para a Europa, ficam logo sujeitas a um processo de rotulagem social: $O$ único problema é os vizinhos, porque mesmo que não estivesse na prostituição, brasileira que vem para Portugal é prostituta, não adianta! (brasileira, 31 anos).

${ }^{10} \mathrm{O}$ conceito de etnicidade e a categoria social «raça» têm sido objecto de amplo debate e problematização no âmbito das ciências sociais, muito em particular na antropologia. Ver, entre outros, Anthias e Yuval-Davis (1993), Wade (1997), Herskovits (1970), Lévi-Strauss (1996) e Almeida (2000).

${ }^{11} \mathrm{Na}$ esteira da filosofia fenomenológica de Merleau-Ponty (1962), o corpo é entendido por Bourdieu (1977) e Csordas (1990), respectivamente através dos conceitos de «corpo socialmente informado» e de «embodiment», como um lugar de manifestação da cultura e, por inerência, da alteridade. 
No contexto de construção de atributos estigmatizantes que aqui consideramos é evidente a indissociabilidade das categorias de género, «raça» e nacionalidade, constituindo, por isso, «interseccionalidades» (McClintock, 1995; Piscitelli, 2008) que, nas suas dinâmicas conjuntas, produzem ordenamentos simbólicos de diferenciação social. As três encontram-se densamente articuladas sob o estigma puta, que acaba por funcionar como elemento sancionatório do cruzamento (socialmente tido como ilegítimo) de «fronteiras etno-sexuais» (Nagel, 2000). É imperioso relevar que nenhuma das características associadas às categorias atrás referidas, e que induzem a projecção do estigma, está especificamente ligada à prática da prostituição. Mesmo o tipo de vestuário que as mulheres brasileiras usam, embora comparativamente aos padrões locais se apresente mais «ousado», não difere do que é comum elas usarem nos seus quotidianos de origem, como de resto se pode comprovar, entre outros, através das telenovelas brasileiras exibidas nas televisões europeias.

Embora as características em análise não estejam relacionadas com o exercício do trabalho sexual, no contexto das regiões estudadas elas foram sendo convertidas em sinais aos quais corresponde a categoria social puta. Estes sinais fenotípicos e étnicos funcionam, portanto, como poderosos marcadores que suscitam e atraem as projecções simbólicas estigmatizantes. Só assim se explica a estigmatização que recai sob mulheres que não trabalham na prostituição, mas evidenciam os marcadores em causa e a menor incidência do estigma em relação às mulheres prostitutas de perfil menos «brasileiro». Podemos, então, pressupor que o processo de estigmatização em causa remete também para (ou está articulado com) a condição de alteridade exótica das mulheres a que, directa e imediatamente, se refere e sobre as quais arremessa uma determinada representação identitária ${ }^{12}$.

Enquanto projecção e demarcação de uma identidade marginal, o estigma puta emerge dos fantasmas de poluição da identidade que assombram os discursos mais recorrentes de pendor moralista sobre a prostituição e sobre as relações de género. Daí o desconforto de partilhar os mesmos espaços e estar próximo das trabalhadoras sexuais: Eu tinha vergonha de acompanhar com eles [irmão e respectiva companheira, a trabalhar na prostituição], porque a gaja não é uma mulher que se apresentasse. Ele deixou uma mulher trabalhadora para se juntar a um traste destes! (cliente de clubes, 26 anos). Como se pode constatar neste excerto, o incómodo de as acompanhar no espaço público é, muitas vezes, manifestado mesmo por parte daqueles que as procuram nos clubes.

\section{Repressão e exclusão}

Os discursos e comportamentos individuais de censura moral das mulheres prostitutas são, em alguns casos, acompanhados por acções mais concertadas e organizadas de repressão, tais como a recolha de assinaturas a exigir a sua expulsão de prédios de habitação, de localidades e mesmo do país, a apresentação de queixas variadas junto das autoridades e a constituição de movimentos públicos de protesto. $\mathrm{O}$ exemplo com maior impacto mediático destes tipo de iniciativas dos «fazedores da moral» (Becker, 1966) foi a eclosão, no início de Maio de 2003, do chamado «Movimento das Mães de Bragança» (MMB). Através de um manifesto apresentado à comunicação social, um grupo de três mulheres da cidade de Bragança responsabilizava as prostitutas pela degradação dos respectivos ambientes familiares. Os seus protestos centraram-se nas prostitutas de nacionalidade brasileira, culpando-as pelo comportamento dos maridos e pelo fim dos respectivos casamentos e, por isso, exigindo uma célere e eficaz intervenção das autoridades competentes ${ }^{13}$.

$\mathrm{O}$ MMB teve uma duração efémera e nem mesmo o sensacionalista artigo da Time-Europe Magazine (Ripley, 2003) que, absurdamente, apelidava Bragança como o novo red light

12 Como referimos em texto anterior (Ribeiro e Sacramento, 2005), poder-se-á mesmo assumir a existência de uma dupla estigmatização: pela actividade exercida e, cumulativamente, pela condição de estrangeiras.

13 Para um conhecimento mais detalhado deste movimento e das circunstâncias em que surgiu, vejamse Ribeiro et al. (2007) e Machado Pais (2010). 
district da Europa, contribuiu para a sua reanimação ${ }^{14}$. As razões da efemeridade de um movimento, que praticamente nem chegou a sê-lo, poder-se-ão imputar, entre outros, ao carácter artificial da sua génese (impulsionado e explorado pelos media) e ao facto de estar associado a situações muito pontuais. Todavia, a enorme atenção mediática que recebeu ${ }^{15}$ e o pânico moral que daí resultou fizeram com que o MMB fosse oportunamente aproveitado como factor implícito de justificação da intervenção repressiva do Estado português no campo da prostituição. Os receios de contágio identitário e os fantasmas da desordem moral -indissociáveis da secular colonização ideológica preconizada pela Igreja católica-, aliados a argumentos pouco fundamentados que apontam o sexo mercantil como um perigoso foco epidemiológico e criminológico ${ }^{16}$, constituem quase sempre o lastro social impulsionador deste tipo de intervenções. Estas incluem inúmeros procedimentos de controlo institucional das trabalhadoras sexuais (v.g. vigilância jurídica e policial, superintendência médica, intervenção de técnicos sociais), que, directa ou indirectamente, acabam por reforçar os estigmas, as diferenças e os valores patriarcais (Silva, Machado e Silva, 2002; Juliano, 2005; Silva, 2007; Sanders, 2009; Oliveira, 2009) propalados pela moral hegemónica (Lewis, Shaver e Maticka-Tyndale, 2013).

Na sequência da exploração mediática do MMB foram desencadeadas um pouco por todo o país, e com maior incidência no nordeste da região de Trás-os-Montes, diversas acções de fiscalização sistemática aos clubes, por parte das autoridades policiais. Como resultado destas investidas, a prostituição de clubes no distrito de Bragança, por exemplo, foi praticamente eliminada: estabelecimentos encerrados, muitos dos proprietários detidos sob acusação de lenocínio e trabalhadoras sexuais «ilegais» deportadas. No início de 2013, volvida quase uma década, apenas três clubes estavam em funcionamento na região. Todavia, isto não significa que a estratégia seguida pelas autoridades tenha tido êxito. Apesar da intensa cruzada de que foi alvo, a prostituição não foi eliminada, apenas se reconfigurou; situação bastante comum sempre que é seguida uma abordagem repressiva. Muitas das mulheres deslocaram-se para os territórios fronteiriços adjacentes de Castilla y Léon, cujos clubes têm, desde então, registado uma procura acrescida por parte de clientes portugueses ${ }^{17}$. Outras permaneceram em Bragança, onde a actividade se tornou menos visível, passando a ser exercida, predominantemente, em apartamentos arrendados pelas próprias ou por terceiros. Nestas circunstâncias, a angariação da clientela é feita, de forma muito subtil, no espaço público e, principalmente, através da ampla rede de contactos que as mulheres vão construindo.

As reconfigurações do mercado do sexo em Bragança mostram-nos que a coibição judicial e o acosso policial não são as estratégias mais adequadas para o Estado intervir na prostituição e combater os seus eventuais problemas. A

$14 \mathrm{O}$ artigo da Time não teve impacto no MMB, mas teve um papel muito relevante, sobretudo à escala nacional, na produção de configurações identitárias estigmatizadas — territorializadas (Chaves, 1999) nas quais Bragança era (é) apresentada como uma cidade de putas. As narrativas mediáticas, como se pode constar no trabalho de Hallgrímsdóttir et al. (2008), interferem decisivamente na produção e na mutabilidade histórica dos estigmas relacionados com a prostituição.

15 Um bom indicador desta atenção são os cerca de 250.000 resultados existentes no Google (Março de 2013 ) para a expressão «Mães de Bragança», distribuídos por vídeos no Youtube, comentários em blogs, referências em artigos científicos, notícias de jornal e, inclusivamente, uma entrada na Wikipédia.

${ }^{16}$ Ao longo da história e em diferentes contextos, a prostituição feminina tem sido sistematicamente estereotipada como um contexto de disseminação de infecções sexualmente transmissíveis (IST) (Parent, 2001; Scambler, 2007; East, Debra, O’Brien e Peters, 2012), de perigos e de «marginalidades» (Walkowitz, 1991; Parent e Coderre, 2000). Contrariando alguns destes estereótipos, em trabalho anterior (Ribeiro, Silva, Ribeiro e Sacramento, 2005) mostrou-se que a incidência de IST entre trabalhadoras sexuais de clubes não é relevante e não difere do que acontece entre a generalidade da população.

17 No sentido de tirar proveito desta nova situação, alguns destes clubes espanhóis têm vindo a apostar em estratégias de marketing e em iniciativas directamente dirigidas à clientela de Portugal, recorrendo, por exemplo, a anúncios publicitários em rádios locais portuguesas. Sobre este processo de deslocalização transfronteiriça da prostituição, veja-se, ainda, Machado Pais (2010). 
repressão torna o fenómeno ainda mais subterrâneo e «marginal», o que origina a degradação das condições de prestação de serviços sexuais, o disempowerment das mulheres e a redução das possibilidades de beneficiarem do acompanhamento de instituições públicas e associativas. Ficam, deste modo, enredadas numa extensa vulnerabilidade social, excluídas do conjunto de direitos básicos de que deverão beneficiar todos os cidadãos, independentemente do seu trabalho (Seshu, 2008).

Simultaneamente, ao serem empurradas para as margens da sociedade, os estigmas intensificam-se, tornando ainda mais graves as inúmeras consequências negativas que a eles tendem a estar associadas: inibição do acesso a serviços básicos (v.g. saúde), stress, ansiedade, medo da exposição da identidade e permanente esforço de gestão da mesma, exaustão emocional, défice de participação cívica, baixas expectativas pessoais para o futuro, dificuldade para abandonar a prostituição, violência interpessoal e institucional (Scambler, 2004; Vanwesenbeeck, 2005; Tomura, 2009; Cornish, 2006; Oliveira, 2009; Oselin, 2009; Sallmann, 2010). Para combater de forma estrutural e sustentada os efeitos da estigmatização, julgamos decisivo que países como Portugal e Espanha abandonem definitivamente o limbo jurídico em que está prostituição e adoptem uma «legalização desestigmatizante» da actividade, equiparando-a a qualquer outro trabalho em termos de direitos e de deveres (Ribeiro et al., 2007; Ribeiro, 2007).

\section{Concluindo: o estigma como meio de controlo da feminilidade}

$\mathrm{O}$ processo de estigmatização que temos vindo a debater, apesar de incidir mais directa e intensamente sobre as mulheres que exercem a prostituição, tem, contudo, um alcance de maior amplitude. Ele pode recair sobre qualquer mulher, constituindo-se como um anátema a que a condição feminina está permanentemente sujeita. Com efeito, o rótulo puta, mais que a conceptualização de características específicas das mulheres que se prostituem ${ }^{18}$, representa, acima de tudo, uma construção social sancionatória da transgressão dos valores hegemónicos que regulam a intimidade e as relações de género. Simultaneamente, expressa muitos dos fantasmas ainda existentes em relação à sexualidade, sobretudo à feminina, e, bem assim, o forte investimento dispendido no seu controlo por parte de uma sociedade em que prevalece a «dominação masculina» (Bourdieu, 1999).

A propósito dos fantasmas sociais sobre a sexualidade feminina, Bourdieu (1999, p. 14) destaca que «é evidentemente porque a vagina continua a ser constituída em fetiche e tratada como sagrada, secreta e tabu, que o comércio do sexo continua a ser estigmatizado». A mulher que não assegurar a sacralidade genital, desrespeitando os padrões sexuais e de género socialmente prescritos — esteja ou não a trabalhar na prostituição, haja ou não um «reconhecimento cognitivo» (Goffman, 1982) por terceiros do seu percurso biográfico - corre o risco de ser catalogada de puta. Esta catalogação parece ser particularmente pejorativa no caso das mulheres que, embora não exercendo a prostituição, evidenciam comportamentos sexuais tidos como atípicos no âmbito da hegemonia patriarcal e para os quais, alegadamente, não há as atenuantes (v.g. a necessidade) que, muitas vezes, são tidas em conta na apreciação das que se prostituem:

- Muitas das mulheres que estão ali [clubes] têm marido ou namorado e não andam com mais ninguém. Aquilo para elas é como um trabalho qualquer. Há muitas mulheres fora, as ditas normais, que põem os cornos aos maridos. $30 \%$ das mulheres casadas traem os maridos. Essas é que são infiéis [essas é que são putas]! (cliente, 43 anos);

- Eu acho que crime é uma puta casada que anda a cornear [enganar] o marido às escondidas! Para mim, essas é que são as verdadeiras putas! As outras, é uma profissão. Como é que sobrevivem, se não há empregos para todas? É a vida fácil e dará mais dinheiro também (cliente, 40 anos).

Reprovam-se, desta forma, comportamentos divergentes daquilo que é considerado normal,

18 Ainda que, tal como já referimos, determinadas características de algumas dessas mulheres, que não decorrem da actividade que exercem, possam ser tomadas pela generalidade das pessoas como sinónimos da prática da prostituição. 
tendo em conta o sistema predominante de valores que define a identidade social do género feminino. Para garantir a conformidade a esta identidade, a mulher deverá corresponder às expectativas inerentes ao modelo ideal de esposamãe, gerindo reservadamente o seu corpo e a sua sexualidade. Quando tal não acontece e a normalidade é posta em causa, emergem anticorpos sociais (a ideologia do desvio e o estigma) para reprovar as responsáveis: No homem é normal [a actividade sexual extra-conjugal], na mulher não é um comportamento normal! Elas também têm desejos como nós, mas fica mais mal visto numa mulher que num homem. [...] Iam chamar-lhe o nome duma prostituta! (cliente, 19 anos).

O controle social da feminilidade, no qual o elemento simbólico puta desempenha um papel central, permite-nos concluir que a estigmatização das trabalhadoras sexuais é apenas a face mais imediatamente visível da repressão que recai sobre a maioria das mulheres. Sustentada por quadros ideológicos como o da «honra-vergonha» (Pheterson, 1993; Silva, 2002), ela é exercida por via daquilo que Bourdieu (1999) designa de «violência simbólica»; que se caracteriza por uma adesão das dominadas, assumida como natural e inquestionável, aos quadros de conhecimento dos dominantes. Trata-se, como destaca Favret-Saada (1987), de uma «submissão encantada», com base na qual

[...] os dominados aplicam aos que os dominam esquemas que são o produto da dominação, ou, noutros termos, quando os seus pensamentos e as suas percepções se estruturam em conformidade com as próprias estruturas da relação da dominação que lhes é imposta, os seus actos de conhecimento são, inevitavelmente, actos de reconhecimento, de submissão (Bourdieu, 1999, p. 12).
A convergência entre as estruturas cognitivas e as estruturas objectivas da realidade socia $^{19}$ induz uma visão subjectiva das identidades de género e das assimetrias que lhes são inerentes como algo natural e normal. As diferenças fisiológicas entre os sexos são invocadas como principais argumentos para explicar e legitimar a supremacia masculina, «inscrevendo-a numa natureza biológica que é ela própria uma construção social naturalizada» (Bourdieu, 1999, p. 20). A relação de dominação impõe-se, então, aos olhos dos actores sociais como uma essência natural, imutável e, por isso, inquestionável. É neste sentido que Bourdieu (1999) se refere as próprias mulheres como «cúmplices» da dominação masculina, já que, amiúde, agem de acordo com os pressupostos sociais (naturalizados e tomados como inevitáveis) que sustentam as desigualdades de género.

A reacção da comunidade feminina em geral ao fenómeno da prostituição é um bom exemplo desta «cumplicidade». Mulheres como as «Mães de Bragança» tendem a estigmatizar as prostitutas e a culpá-las de lhes tumultuarem e mesmo destruírem a vida familiar. Mas, praticamente, não põem em causa, ou pelo menos não o fazem com equivalente acutilância, o comportamento sexual dos respectivos maridos, em boa parte por o considerarem natural, logo desculpável. Terminamos ressalvando a actualidade das considerações tecidas há dois séculos atrás por Engels (1964), quando sublinhou que a prostituição é uma instituição social que assegura a liberdade sexual a favor do homem e que a reprovação moral que dela decorre não atinge apenas as mulheres que a exercem.

\section{Referênces}

Abel, G. e Fitzgerald, L. (2010). Decriminalisation and stigma. Em G. Abel, L. Fitzgerald, C. Healy e A. Taylor (Eds.). Taking the crime out of sex work: New Zealand sex workers' fight for decriminalisation (pp. 239-258). Bristol: The Policy press.

Almeida, M. (2000). Um mar da cor da terra: 'raça', cultura e política da identidade. Oeiras: Celta. Anthias, F. e Yuval-Davis, N. (1993). Racialized boundaries: race, nation, gender, colour and class and the anti-racist struggle. Londres: Routledge.

Bastos, S. (1997). O Estado Novo e os seus vadios: contribuição para o estudo das identidades marginais e da sua repressão. Lisboa: D. Quixote.

Becker, H. (1966). Outsiders: studies in the sociology of deviance. Toronto: Free Press.

Becker, H. (1977). Uma teoria da acção colectiva. Río de Janeiro: Zahar.

${ }^{19}$ Corresponde àquilo que Husserl (in Bourdieu, 1999) designa de «experiência dóxica». 
Bourdieu, P. (1999). A dominação masculina. Oeiras: Celta.

Chaves, M. (1999). O estigma como espelho: notas sobre a deterioração de uma identidade territorializada. Fórum Sociológico, 1-2(2a série), pp. 289-319.

Budin, S. (2006). Sacred prostitution in the first person. Em C. Faraone e L. MacClure (Eds.). Prostitutes \& courtesans in the ancient world (pp. 77-93). Madison: Wisconsin University Press.

Cornish, F. (2006). Challenging the stigma of sex work in India: material context and symbolic change. Journal of Community \& Applied Social Psychology, 16(6), pp. 462-471. doi: 10.1002/casp.894.

Csordas, T. (1990). Embodiment as a paradigm for Anthropology. Ethnos, 18(1), pp. 5-47. doi: 10.1525/eth.1990.18.1.02a00010.

Douglas, M. (1976). Pureza e perigo. São Paulo: Perspectiva.

Duarte, M. (2012). Prostitution and trafficking in Portugal: legislation, policy, and claims. Sexuality Research and Social Policy, 9(3), pp. 258-268. doi: 10.1007/s13178-012-0093-2.

East, L., Debra, J., O’Brien, L. e Peters, K. (2012). Stigma and stereotypes: women and sexually transmitted infections. Collegian - Journal of the Royal College of Nursing Australia, 19(1), pp. 15-21. doi: 10.1016/j.colegn.2011.10.001.

Engels, F. (1964 [1884]). A origem da família, da propriedade privada e do Estado. Rio de Janeiro: Vitória.

Favret-Saada, J. (1987). L'arraisonnement des femmes. Les Temps Modernes, Fev., pp. 137-150.

Guimarães, K. e Merchán-Hamann, E. (2005). Comercializando fantasias: a representação social da prostituição, dilemas da profissão e a construção da cidadania. Estudos Feministas, 13(3), pp. 525-544.

Goffman, E. (1982 [1963]). Estigma: notas sobre a manipulação da identidade deteriorada. Rio de Janeiro: Zahar.

Goffman, E. (1993). A apresentação do eu na vida de todos os dias. Lisboa: Relógio d'Água.

Gonçalves, M. (2007). Código penal português. Coimbra: Almedina.

Hallgrímsdóttir, H., Phillips, R., Benoit, C. e Walby, K. (2008). Sporting girls, streetwalkers, and inmates of house of ill repute: media narratives and the historical mutability of prostitution stigmas. Sociological Perspectives, 51(1), pp. 119-138. doi: 10.1525/sop.2008.51.1.119.

Hart, A. (1998). Buying and selling power: anthropological reflections on prostitution in Spain. Oxford: Westview Press.

Herskovits, M. (1970 [1941]). The myth of the negro past. Boston: Beacon Press.

Jacobsen, C. e Skilbrei, M. (2010). 'Reproachable victims'? Representations and self-representations of Russian women involved in transnational prostitution. Ethnos, 75(2), pp. 190-212. doi: $10.1080 / 00141841003764013$.

Juliano, D. (2005). El trabajo sexual en la mira. Polémicas y estereotipos. Cadernos Pagu, 25, pp. 79-106.

Leick, G. (2008). Sexuality and religion in Mesopotamia. Religion Compass, 2(2), pp. 119-133. doi: $10.1111 / \mathrm{j} .1749-8171.2008 .00063 . x$.

Lemert, E. (1972). Human deviance, social problems, and social control. Nova Jérsia: Prentice Hall.

Lévi-Strauss, C. (1996 [1952]). Raça e História. Lisboa: Presença.

Lewis, J., Shaver, F. e Maticka-Tyndale, E. (2013). Going 'round again: the persistence of prostitution-related stigma. Em E. van der Meulen, E. Durisin e V. Love (Eds.). Selling sex: experience, advocacy, and research on sex work in Canada (pp. 198-208). Vancouver: UBC Press.

Liberto, H. (2009). Normalizing prostitution versus normalizing the alienability of sexual rights: a response to Scott A. Anderson. Ethics, 120(1), pp. 138-145. doi: 10.1086/644624.

McClintock, A. (1995). Imperial leather: race, gender and sexuality in the colonial contest. Londres: Routledge.

Machado Pais, J. (2010). 'Mães de Bragança' e feitiços: enredos luso-brasileiros em torno da sexualidade. Revista de Ciências Sociais, 41(2), pp. 9-23. 
Merleau-Ponty, M. (1962). Phenomenology of perception. Londres: Routledge.

Nagel, J. (2000). Ethnicity and sexuality. Annual Revue of Anthropology, 26, pp. 107-133.

Nahra, C. (2000). Malditas defesas morais. Natal: Cooperativa Cultural.

Oliveira, A. (2009). Violência sobre trabalhadores do sexo ou a reacção social à prostituição de rua. Em M. Silva e F. Ribeiro (Eds.). Mulheres da vida, mulheres com vida: prostituição, Estado e políticas (pp. 107-121). Ribeirão: Húmus.

Oliveira, A. (2011a). Andar na vida: prostituição de rua e reacção social. Coimbra: Almedina.

Oliveira, A. (2011b). Uma pesquisa etnográfica sobre prostituição de rua: do saber ao fazer. Em P. Silva, O. Sacramento e J. Portela (Eds.). Etnografia e intervenção social: por uma praxis reflexiva (pp. 245-269). Lisboa: Colibri.

Oselin, S. (2009). Leaving the streets: transformation of prostitute identity within the prostitution rehabilitation program. Deviant Behavior, 30(4), pp. 379-406. doi: 10.1080/ 01639620802258485.

Oselin, S. (2010). Weighing the consequences of a deviant career: factors leading to an exit from prostitution. Sociological Perspectives, 53(4), pp. 527-550. doi: 10.1525/sop.2010.53.4.527.

Parent, C. e Coderre, C. (2000). Le corps social de la prostituée: regards criminologiques. Em S. Frigon e M. Kérésit (Eds.). Du corps des femmes: contrôles, surveillances, résistances (pp. 93124). Ottawa: Presses de l' Úniversité d'Ottawa.

Parent, C. (2001). Les identités sexuelles et les travailleuses de l'industrie du sexe à l'aube du nouveau millénaire. Sociologie et Sociétés, 32, 1, pp. 159-178. doi: 10.7202/001544ar.

Piscitelli, A. (2007). Corporalidades em confronto: brasileiras na indústria do sexo na Espanha. Revista Brasileira de Ciências Sociais, 22(64), pp. 17-32. doi: 10.1590/S010269092007000200002.

Piscitelli, A. (2008). Interseccionalidades, categorias de articulação e experiências de migrantes brasileiras. Sociedade e Cultura, 11(2), pp. 263-274.

Pheterson, G. (1993). The whore stigma: female dishonor and male unworthiness. Social Text, 37 , pp. 39-64.

Pheterson, G. (1996). The prostitution prism. Amesterdão: Amsterdam University Press.

Pons, I. e Serra, V. (1998). Female prostitution in Spain: neither criminals nor victims. Em J. Elias, V. Bullough e G. Brewer (Eds.). Prostitution: on whores, hustlers and johns (pp. 493-500). Nova Iorque: Prometheus Books.

Pontes, L. (2004). Mulheres brasileiras na mídia portuguesa. Cadernos Pagu, 23, pp. 229-256.

Ribeiro, F. (2007). Proibições, abolições e a imaginação de políticas inclusivas para o trabalho sexual. Bagoas, 1(1), pp. 17-31.

Ribeiro, F. e Sacramento, O. (2009). Imagens, erotismo e culturas on the road: perspectivas sobre o Brasil como destino turístico. Configurações, 5-6, pp. 241- 255.

Ribeiro, F. e Sacramento, O. (2012). Viver com a infecção: gestão da doença e quotidianos terapêuticos de doentes com VIH/sida no nordeste de Portugal. Revista Angolana de Sociologia, 10, pp. 111-130.

Ribeiro, M. (2004, Maio, 12-15). As prostitutas também são mães: contornos e conteúdos de uma condição (quase sempre) extrema. Actas dos ateliers do V Congresso Português de Sociologia - Sociedades Contemporâneas: Reflexividade e Acção. [Online]. Disponível em: http://www.aps.pt/cms/docs_prv/docs/DPR4628c5ed94ee1_1.pdf (10 de Março de 2013).

Ribeiro, M. e Sacramento, O. (2002). Prostituição feminina no espaço transfronteiriço ibérico: um caso muito particular de circulação de pessoas. Cadernos do Noroeste, 18(1-2), pp. 205-227.

Ribeiro, M. e Sacramento, O. (2005). Violence against prostitutes: findings of research in the Spanish-Portuguese frontier region. European Journal of Women's Studies, 12(1), pp. 61-81. doi: $10.1177 / 1350506805048856$.

Ribeiro, M., Silva, M., Ribeiro, F. e Sacramento, O. (2005). Prostituição abrigada em clubes (zonas fronteiriças do Minho e de Trás-os-Montes): práticas, riscos e saúde: Lisboa: CIDM.

Ribeiro, M., Silva, M., Schouten, J., Ribeiro, F. e Sacramento, O. (2007). Vidas na raia: prostituição feminina em regiões de fronteira. Porto: Afrontamento. 
Ringdal, N. (2004). Love for sale: a world history of prostitution. Nova Iorque: Grove Press. Ripley, A. (2003). When the 'meninas' came to town. TIME Europe Magazine, 162, p. 15.

Roberts, N. (1996). A prostituição através dos tempos na sociedade ocidental. Lisboa: Presença.

Sallmann, J. (2010). Living with stigma: women's experiences of prostitution and substance use. Affilia, 25(2), pp. 146-159. doi: 10.1177/0886109910364362.

Sanders, T. (2009). Controlling the 'anti sexual' city: sexual citizenship and the disciplining of female street sex workers. Criminology and Criminal Justice, 9(4), pp. 507-525. doi: $10.1177 / 1748895809343403$.

Scambler, G. (2004). Re-framing stigma: felt and enacted stigma and challenges to the sociology of chronic and disabling conditions. Social Theory and Health, 2, pp. 29-46. doi:10.1057/palgrave.sth.8700012.

Scambler, G. (2007). Sex work stigma: opportunist migrants in London. Sociology, 41, pp. 10791096. doi: $10.1177 / 0038038507082316$.

Scott, A. (2010). Os portugueses. São Paulo: Contexto.

Seshu, M. (2008). Surfacing voices from the underground. Em R. Sahni, V. Shankar e H. Apte (Eds.). Prostitution and beyond: an analysis of sex work in India (pp. 195-203). Nova Deli: Sage.

Silva, M., Machado, H. e Silva, S. (2002). Direito, ciência e o corpo feminino: a prostituição como objecto de fronteira, Cadernos do Noroeste, 18(1-2), pp. 183-203.

Silva, M. (2002). Honra-vergonha: código cultural mediterrânico ou forma de controlo patrimonial e sócio-político de mulheres?. Trabalhos de Antropologia e Etnologia, 42(3-4), pp. 125-144.

Silva, S. (2007). Classificar e silenciar: vigilância e controlo institucionais sobre a prostituição feminina em Portugal. Análise Social, 42(184), pp. 789-810.

Sverdljuk, J. (2009). Contradicting the 'prostitution stigma': narratives of Russian migrant women living in Norway. Em S. Keskinen, S. Tuori, S. Irni e D. Mulinari (Eds.). Complying with colonialism: gender, race and ethnicity in the Nordic region (pp. 137-153). Surrey: Ashgate.

Tomura, M. (2009). A prostitute's lived experiences of stigma. Journal of Phenomenological Psychology, 40, pp. 51-84. doi: 10.1163/156916209X4 27981.

Vanwesenbeeck, I. (2005). Burnout among female indoor sex workers. Archives of Sexual Behavior, 34(6), pp. 627-639. doi: 10.1007/s10508-005-7912-y.

Wade, P. (1997). Race and ethnicity in Latin América. Londres: Pluto Press.

Walkowitz, J. (1991). Sexualités dangereuses. Em G. Duby e M. Perrot (Eds.). Histoires des Femmes en Occident, le XIX Siècle (pp. 389-418). Paris: Plon.

Wolputte, S. (2004). Hang on to your self: of bodies, embodiment, and selves. Annual Revue of Anthropology, 33, pp. 251-269. doi: 10.1146/annurev.anthro.33.07 0203.143749. 